\title{
O PARFOR NA AMAZÔNIA PARAENSE: reflexões sobre a formação inicial de professores em exercício
}

\author{
Evaldo Ferreira Rodrigues ${ }^{1}$ \\ Waldir Ferreira de Abreu²
}

\section{RESUMO}

Este artigo discute a formação inicial de professores no Brasil ao tomar como ponto de partida as influências dos organismos internacionais, como o FMl, O BM e a OCDE, na definição das políticas educacionais brasileiras até o atual Plano Nacional de Formação de Professores da Educação Básica (PARFOR) no Brasil e, particularmente, seu reflexo no Estado do Pará. A metodologia consistiu em um estudo bibliográfico de obras sobre a interface entre o capital e a formação de professores baseado em Ferreira (2011), Maués (2011), Mészáros (2005), Gatti, Sá e André (2011) e Freitas (2003, 2007), além de documentos oficiais da política educacional do estado do Pará encontrados no Plano Decenal de Formação docente do Estado do Pará $(2009 ; 2011)$ e no relatório de avaliação do PARFOR (2013). Concluímos que os organismos internacionais desde a década de 1970 influenciam nas políticas de formação de professores no Brasil, quer seja por meio de financiamento ou por recomendações, e neste quadro encontra-se a gênese do PARFOR de forma consensual e consentida pelo governo federal, estadual e local. Por fim, este estudo revela a urgência na tomada de decisão em relação às instituições e aos profissionais envolvidos no PARFOR, no sentido de qualificar o processo formativo a partir das necessidades, particularidades e territorialidades onde o plano é implementado, em efetiva partilha de responsabilidades entre os entes federados, com um regime global de colaboração e cooperação que perpassa por profundas mudanças na política de formação de professores no Brasil e na Amazônia.

Palavras-chave: Organismos Internacionais. Formação de Professores. PARFOR.

1 Doutorando do Programa de Pós-Graduação em Educação (PPGED) da Universidade Federal do Pará (UFPA); Mestre em Educação e Especialista em Educação e Informática. Professor Assistente IV da Universidade do Estado do Pará (UEPA). Belém, Pará, Brasil. Orcid iD: https://orcid.org/0000-0002-031 1-9723. E-mail: evalldoo71@gmail.com

2 Pós-Doutor em Ciências da Educação - Espanha (2013); Doutor em Ciências Humanas e Educação pela PUC-Rio (2010); Mestre em educação e Políticas Públicas pela Universidade Federal do Pará (2002). Professor Associado da Universidade Federal do Pará. Belém, Pará, Brasil. Orcid iD: https://orcid.org/0000-0002-0245-9072. E-mail: awaldir@ufpa.br 


\title{
PARFOR IN THE AMAZON IN PARÁ: reflections on the initial training of in-service
}

\author{
teachers
}

\begin{abstract}
This article discusses the initial formation of teachers in Brazil taking as a starting point the influences of the international bodies such as the IMF, the WB and the OECD in the definition of the educational policies of the brazilian until the current Plano Nacional de Formação de Professores da Educação Básica (PARFOR) in Brazil and its reflection in Pará. The methodology was a literature study of works about the interface between the capital and the training of teachers, based on Ferreira (2011), Maués (2011), Mészáros (2005), Gatti, Sá and André (2011) and Freitas (2003, 2007), in addition to the official documents of the educational policy of the state of Para found in the ten year Plan for teacher Education of the State of Pará $(2009 ; 2011)$ and in the report of the evaluation of the PARFOR (2013). We conclude that the international bodies since the 1970s influenced the policies of training of teachers in Brazil, whether by funding or by recommendations, and in this framework is the genesis of the PARFOR consensus. Finally, this study reveals the urgency in decisionmaking in relation to the institutions and professionals involved in the PARFOR, in the sense of qualifying the training process from needs, the characteristics and territorialities where the plan is implemented, effective sharing of responsibilities among the federated entities, with a global regime of collaboration and cooperation that permeates the profound changes in the politics of formation of teachers in Brazil and in the Amazon.
\end{abstract}

Keywords: International Organizations. Teachers' Training. PARFOR.

\section{EL PARFOR EN LA AMAZONIA PARAENSE: reflexiones sobre la formación inicial de profesores en ejercicio}

\section{RESUMEN}

En este artículo se analiza la formación inicial de profesores en Brasil, al tomar como punto de partida las influencias de los organismos internacionales, como FMI, BM y $\mathrm{OCDE}$, en la definición de las políticas educativas brasileñas hasta el actual Plan Nacional de Formación de Profesores de Educación Básica (PARFOR) en Brasil y, en particular, su reflejo en Pará. La metodología consistió en un estudio bibliográfico de obras sobre la interfaz entre el capital y la formación de profesores basado en Ferreira (2011), Maués (2011), Mészáros (2005), Gatti, Sá y André (2011) y Freitas $(2003,2007)$, además de los documentos oficiales de la política educativa de Pará encontrados en el Plan de Formación docente del Estado de Pará $(2009 ; 2011)$ y en el informe de evaluación del PARFOR (2013). Concluimos que los organismos internacionales desde 1970 influyen en las políticas de formación de profesores en Brasil, ya sea por medio de financiación o por recomendaciones, y en este marco se encuentra la génesis del PARFOR de forma consensuada y consentida por el gobierno. Por último, este estudio revela la urgencia en la toma de decisiones en relación a las instituciones y a los profesionales involucrados en el PARFOR, para calificar el proceso formativo a partir de las necesidades, particularidades y 
territorialidades en que el plan se implementa, en efectivo reparto de responsabilidades entre los entes federados, con un régimen global de cooperación por el que atraviesa profundos cambios en la política de formación de profesores en Brasil.

Palabras clave: Organismos Internacionales. Formación de Profesores. PARFOR.

\section{INTRODUÇÃO}

Ao debatermos a formação de professores no Brasil e no Pará é importante partirmos das mudanças ocorridas no cenário nacional e internacional nos últimos trinta anos, as quais estão relacionadas à crise do sistema capitalista em nível mundial, cuja solução é vista no cumprimento das exigências econômicas impostas por meio de ajustes fiscais direcionados a países emergentes como os da América Latina e Caribe, onde está inserido o Brasil.

Na realidade brasileira é possível detectar essas mudanças nas reformas oficiais a partir da década de 1970, quando o sistema educacional é adequado aos processos de reestruturação produtiva do Estado, os quais são traduzidos em um projeto pautado no ideário neoliberal em que a educação e a formação de professores da educação básica são vistos como estratégias para a manutenção e acúmulo do capital.

Os grandes intermediários do ideário exposto são os organismos internacionais - quer financiando, quer fazendo recomendações aos países tomadores de empréstimos financeiros - como o Fundo Monetário Internacional (FMI), o Banco Mundial (BM) e a Organização para a Cooperação e Desenvolvimento Econômico (OCDE). Esses organismos proferem discursos em defesa da diminuição da pobreza, aumento do grau de escolarização da população e desenvolvimento do país.

Neste cenário evidenciamos grande preocupação em formar massivamente para o mercado de trabalho alunos a baixo custo, professores de forma aligeirada e sem perspectivas críticas sobre as relações estabelecidas entre educação-trabalho-produção.

A despeito do ensino superior presenciamos, a partir da vigência da Lei de Diretrizes e Bases da Educação (LDB) - n 93994/96, de 20 de dezembro 
de 1996 - a adequação das Instituições de Ensino Superior (IES) à nova lógica do capital em um movimento contínuo, desde a oficialização de instituições não universitárias de natureza privada, como os Institutos Superiores de Educação (ISEs) e as escolas normais superiores, que deságuam no processo de certificação acelerada em longa escala e na formação em serviço; até as suas consequências mais danosas, como a proletarização, a precarização e a intensificação do trabalho do professor.

Em decorrência do quadro exposto, vemos emergir da realidade social demandas educacionais, cujas maiores responsabilidades são transferidas à escola e aos professores, com grande preocupação de inserilos no mercado de trabalho o mais rápido possível, acelerando as suas formações, cujas concepções assentam-se em modelos tradicionais e tecnicistas, no fazer desprovido de teorias focadas nos problemas da escola, da sala de aula e, consequentemente, na sua solução imediata. Por isso, afirmamos a necessidade da revisão desse viés formativo ao enveredar a outros caminhos críticos e alternativos que façam reverberar as multidimensionalidades da formação de professores e sua interface com o contexto social mais amplo.

Neste contexto, debater a formação inicial de professores é uma questão urgente e desafiadora, mesmo entendendo ser um tema bastante estudado, pleiteado e publicizado, ainda é, sobretudo, um "campo minado" com tensões, dilemas e divergências no movimento de construção do projeto de formação que respondam aos anseios e interesses dos professores em formação e em exercício da profissão docente. Por isso, urge a necessidade de analisá-la em coesão com as condições existenciais da carreira profissional, de forma consistente e relacional, com vistas a pleitearmos chegar a resultados de sucessos e êxitos nesta dimensão formativa.

Entretanto, é importante evidenciarmos que a gênese deste artigo assenta-se a partir dos debates e discussões travadas em torno da Formação de Professores na Amazônia durante o segundo semestre do ano de 2017, no âmbito do Programa de Pós-graduação em Educação da Universidade 
Federal do Pará (PPGED/UFPA), cujo objetivo consistiu em aproximá-las ao objeto de estudo do discente vinculado ao referido programa que, no caso desta pesquisa, é a formação inicial de professores em exercício para os anos iniciais do ensino fundamental focada na experiência do PARFOR3.

$\mathrm{Na}$ primeira seção deste artigo discorremos sobre a formação de professores e as influências dos organismos internacionais, como BM, FMI e OCDE, nas políticas de formação de professores no Brasil, nos últimos trinta anos, cujos interesses repousam na lógica capitalista, neoliberal e mercadológica traduzida nas reformas educacionais e de formação de professores, que deram origem aos atuais projetos oficiais do governo brasileiro no campo educacional.

A segunda seção retrata o PARFOR no quadro das ações empreendidas para construção da política nacional de formação de professores da educação básica no Brasil, desde a fase embrionária até os resultados concretos em experiências desenvolvidas em alguns estados brasileiros, ainda condicionados em ordenamentos legais e processos regulatórios, cujas concepções e práticas reproduzem problemas antigos.

Na seção seguinte discutimos do PARFOR no território amazônico, particularmente no estado do Pará, em que os estudos apontam alguns resultados do processo formativo vivenciados no âmbito do Plano em meio a algumas fragilidades e potencialidades que necessitam ser consideradas para melhor qualificar a formação dos professores com atenção às particularidades local e paraense.

Por fim, concluímos ao fazer algumas reflexões e apontamentos sobre os dilemas vividos no PARFOR que nos permitem avaliarmos a formação inicial de professores em exercício do magistério e repensarmos as ações formativas em âmbito nacional, local e paraense.

\footnotetext{
${ }^{3}$ No final do ano de 2017 o governo federal, por meio da CAPES, anunciou o Programa de Formação Inicial e Continuada para Professores da Educação Básica (PROFIC), que objetivava substituir o PARFOR até a conclusão das suas últimas turmas. Além das turmas de graduação, seriam ofertadas especializações em Educação Infantil, Alfabetização, Português e Matemática. No entanto, no início do ano de 2018, o governo anunciou três programas de formação de professores: Programa Institucional de Bolsas de Iniciação à Docência (Pibid); Residência Pedagógica; e Universidade Aberta do Brasil (UAB). A Residência Pedagógica consistiu na novidade neste programa.
} 


\section{AS INFLUÊNCIAS INTERNACIONAIS NA FORMAÇÃO DE PROFESSORES NO BRASIL}

Do final da década de 1970 até a década atual, as reformas educacionais e de formação de professores brasileiras tiveram destaque no quadro das reformas das políticas sociais e, ao serem cada vez mais impulsionadas pela ação dos organismos internacionais, foram materializadas em processos legitimados pela aprovação de leis, resoluções, decretos, planos, projetos, pesquisas e outras formas de regulação.

Mavés (2011, p. 83) chama a atenção ao sublinhar que as regulações encaminhadas pela OCDE:

[...] podem, dependendo do contexto social e político do país no qual essas normas vão se implantar, trazer a marca não só do organismo que define as políticas, mas do Estado que as aceita, dos educadores que as colocam em prática e do mercado que estabelece os parâmetros que servirão para alimentar o sistema.

Esse processo tem o devido consentimento dos governos brasileiros que se sucederam no poder do país durante este período histórico e podemos afirmar ser a LDB $n^{\circ} 9.394 / 96$ um marco de primeira mão no cenário dessas reformas, seguida por ordenamentos legais que a complementam e mudam o seu teor em nome de interesses outros.

Em face do cenário em evidência, vemos uma preocupação com a necessidade do aperfeiçoamento do profissional da educação em que professores, gestores e coordenadores pedagógicos são referenciados como protagonistas nas alusões reformistas do Estado e nas orientações do BM, FMI e OCDE, reforçando o discurso de que a gestão e a formação docente é mola propulsora para o crescimento socioeconômico do Brasil.

Ferreira (2011) lembra que as interferências dos organismos internacionais no Brasil, em especial nas políticas educacionais, advêm desde o período nacional desenvolvimentista com acordos firmados nas diversas áreas sociais ao realizarem empréstimos por meio de financiamento dos bancos de desenvolvimento. Dentre os mais conhecidos cita o Banco Interamericano de Desenvolvimento (BID) e o BM, garantindo tanto a base 
econômica como o controle cultural e político para o desenvolvimento de suas políticas e projetos.

Para Monlevade e Silva (2000), o BM fixa as diretrizes e estratégias para a educação pública brasileira como condição aos empréstimos a serem contraídos, na lógica da competitividade do mercado e do capital, com cláusulas contratuais confabuladas entre a instituição credora e os governos federal e estaduais, de forma a conter os investimentos públicos.

Em relatório de 2017 (GRUPO BANCO MUNDIAL, 2017), os técnicos do BM realizam um balanço dos gastos públicos no Brasil e, no caso da área educacional, além de fazerem comparações equivocadas com o setor privado, deixam a impressão de que se gasta muito no setor público em todos os níveis de ensino. O relatório afirma ser primordial conter tais despesas de modo geral e assevera que na etapa da educação infantil esses gastos foram mais altos se comparado ao ensino médio e ao nível superior na década atual.

Entretanto, o relatório não ressalta que ao serem comparados esses dados entre setor público e privado, deixam de levar em consideração as particularidades e a natureza do trabalho realizado em cada instituição, como o fato de que nas universidades públicas, além das despesas com o ensino, estas são também destinadas à pesquisa, à extensão e a outras atividades acadêmicas de cunho profissional. Acrescentamos ainda o fato de que nas instituições de ensino superior privadas brasileiras, as despesas são particularmente empreendidas com atividades de ensino.

No entanto, vemos um grande paradoxo entre as orientações e práticas dos organismos internacionais, pois de um lado o BM propõe o financiamento na educação, a formação do professor, a escolarização dos alunos e a ampliação da rede pública de ensino; por outro, o FMI impõe cortes de despesas na área pública ao conter gastos e ao praticar ajustes estruturais e, contudo, determina um baixo valor custo-aluno no ensino fundamental em relação a outros níveis de ensino, contrapondo-se a ampliação do investimento na rede escolar como um todo. 
A grande interferência econômica da OCDE nas políticas educacionais brasileiras advém da concepção de que o desenvolvimento econômico de um país depende da qualidade da educação empreendida, a qual está intrinsicamente relacionada com o trabalho docente e, com ele, a responsabilização atribuida aos professores.

Nesta dinâmica, os instrumentos utilizados pelos organismos internacionais estão condicionados às recomendações tomadas em tom de assessoria técnica, mas na realidade contribuem para que as reformas políticas macroeconômicas desenvolvam-se para atender a lógica do capital em suas diversas fases. Diante disto, o Estado brasileiro cede a tais exigências ao adequar a máquina estatal ao cenário das reformas, pautadas no princípio da flexibilidade, eficiência e produtividade.

Seguindo a lógica do capital, a formação dos professores também é condicionada a adequar-se ao referido princípio a partir da intervenção nos processos formativos, na profissão e no trabalho docente para atender aos interesses mercadológicos, os quais são regulados e controlados ao seguir a prerrogativa da "mão invisível" do Estado, conforme apregoado por Smith (1996) no século XVIII e que no século atual ganha proporções cada vez mais globalizadas e mundiais para consolidação do capital.

Porém, em contraposição à lógica mercadológica, compactuamos com Mészáros (2005) ao afirmar que educação não é um negócio, não é mercadoria, e não deve qualificar tão somente para o trabalho, mas para a vida. Isso significa romper radicalmente com a lógica desumanizadora do capital, uma vez ser ele "[...] irreformável porque, pela sua própria natureza, como totalidade reguladora sistêmica, é incontrolável e incorrigível" (MÉSZÁROS, 2005, p. 12-13).

Para o autor, o que está em jogo não é apenas a modificação política dos processos educacionais, mas a transformação da estrutura de valores que contribui para perpetuar a concepção de mundo baseada na sociedade mercantil. Portanto, modificar tais estruturas, concepções e princípios em práticas concretas significa ir para além dos espaços de sala de aula, dos gabinetes e dos fóruns acadêmicos, pois a educação não se 
encerra no terreno da Pedagogia, mas precisa ganhar os espaços das ruas e públicos e se abrir para o mundo.

Ferreira (2011) afirma ser no período da Guerra Fria e da onda crescente da globalização da economia internacional na década de 1990 que a OCDE aproxima-se dos países da América Latina. Para Pinto (2000), isto significa afirmar estar o Brasil no rol dos países da América Latina que conseguiu atingir maior desenvolvimento econômico com êxitos no processo de estabilização e reestruturação econômica.

A interferência da OCDE nas políticas educacionais brasileiras ocorre por meio de programas, pesquisas e publicações no âmbito da educação. Alguns programas são destacados por Ferreira (2011), tais como: Programa Internacional de Avaliação de Estudantes (PISA); Programa Mundial de Indicadores Educacionais (do inglês World Education Indicators - WEI); e a pesquisa TALIS (Teaching and Learning International Survey - Inquérito Internacional sobre Ensino e Aprendizagem). Quanto às publicações, cita-se: "A qualidade do pessoal do ensino" (2004); "Professores são importantes: atraindo, desenvolvendo e retendo professores eficazes" (2006a); "Le capital humain" (2007a); "Politiques d'éducation et de formation" (2007b); "Compreender o impacto social da educação" (2007c); "A educação hoje: a perspectiva da OCDE" (2009b); e, mais recentemente, "Education at a Glance" (2009).

Mavés (2011), ao debater a política da OCDE para a educação e a formação docente, com base nas análises dos documentos produzidos pela referida organização, destaca as formas de regulação assumidas e afirma que, ao adentrar no campo da formação de professores, "traz a marca não só do organismo que define as políticas, mas do Estado que as aceita, dos educadores que as colocam em prática e do mercado que estabelece os parâmetros que servirão para alimentar o sistema" (MAUÉS, 2011, p. 83).

Notamos, portanto, um ciclo ideologizante em que a regulação instaura-se de forma consensual e consentida pelos governos federal, estadual, locais, instituição de ensino e de forma material no exercício 
profissional dos educadores, com ancoragem na retórica em prol do desenvolvimento social, econômico e educacional do país.

A mesma autora adverte estar a política de educação e de formação de professores em processo de transição, passando do modelo burocráticoprofissional para o modelo pós-burocrático, com características próximas do mercado, do lucro e da acumulação. Este modelo está vinculado à política dos resultados, traduzido nas avaliações externas realizadas pelo PISA, cujos resultados devem ser atingidos pelos professores sobre pena de punição, em forma de suspensão do financiamento educacional para a instituição à qual estão vinculados.

É notório que esse modelo responde à lógica neoliberal, capitalista, globalizada e de mundialização, com formas instrumentais baseadas na eficiência e ancorados na meritocracia, que define bons salários e prêmios para os que atingem os resultados preteridos e, por outro lado, desinvestimento nos que não conseguem atingir tais resultados.

Bastos (2013) afirma ter a OCDE a preocupação sobre os países que dela seguem suas recomendações, como o Brasil, de orientar políticas de formação de professores sobre a concepção do "professor eficaz" e "ensino eficaz". Destarte, grandes responsabilidades são atribuídas aos professores que extrapolam suas vontades e condições objetivas e subjetivas de fazê-lo, sobretudo ao referendar um discurso de responsabilização pelos sucessos e fracassos que recaem sobre os professores e desresponsabiliza o Estado em prover educação, ensino e formação de professores com qualidade.

Ferreira (201 1) vislumbra a análise do "professor eficaz", insistentemente defendido nos documentos da OCDE em forma de estímulos para que os governos locais garantam tal modelo de professor em suas políticas de formação de professores e de qualificação do ensino. Ao se contrapor a esses documentos, acredita "[...] que a definição de professor eficaz para tal organização é meramente cognitiva, não vê espaço para o papel político que professor possa vir a exercer na construção do conhecimento da educação" (FERREIRA, 2011, p. 215). 
Sobre esse aspecto, faz-se necessário engendrar uma correlação entre - receituário da OCDE e as políticas de formação de professores desencadeadas no Brasil ao longo dos últimos trinta anos pelo setor educacional, ao analisar até que ponto o país tem se submetido a essas políticas para desenhar o seu modelo de formação docente ou se, por outro viés, tem garantido autonomia aos professores e às instituições formadoras neste campo.

Para isso, utilizamos a análise de Ferreira (2011), ao fazer um parâmetro entre a profissão docente dentro das políticas e orientações da OCDE e as iniciativas brasileiras. De acordo com a referida autora, O PARFOR faz parte desse conjunto de medidas tomadas pelo governo brasileiro sobre influência da organização e, principalmente, dentro da categoria desenvolvimento e implementação de políticas para professores, em que objetivos almejados são: envolver os professores no desenvolvimento e na implementação de políticas; desenvolver comunidades de aprendizagem profissional; e melhorar a base de conhecimentos e apoio às políticas docentes.

\section{O PARFOR COMO POLÍTICA NACIONAL DE FORMAÇÃO DE PROFESSORES:} algumas evidências

A construção da política de formação de professores no Brasil é uma luta histórica desencadeada nos embates entre projetos diferenciados, nos quais estão subjacentes interesses contraditórios e de classes. No caso dos setores progressistas, a luta confunde-se com a própria trajetória de reivindicações dos profissionais da educação representados nas diversas entidades acadêmicas e científicas, que "levantam a bandeira" em defesa da educação de qualidade, pública, gratuita e são partícipes ativos e atuantes na construção dessas políticas, dentre as quais Freitas (2003) destaca: Associação Nacional pela Formação dos Profissionais da Educação (ANFOPE); Associação Nacional de Pós-Graduação e Pesquisa em Educação (ANPED); Fórum Nacional de Diretores de Faculdades das Universidades Públicas Brasileiras (FORUMDIR); e Associação Nacional de Política e Administração da Educação (ANPAE). 
Freitas (2007), ao analisar a formação de professores no Brasil, sublinha algumas situações a serem enfrentadas para a melhoria do quadro em que nos encontramos e para a construção da política de formação de professores no Brasil, a saber: ser configurada em uma política global de formação e valorização dos profissionais da educação articulada entre formação inicial, continuada e condições de trabalho, salários e carreira; estar sustentada na concepção sócio-histórica; garantir igualdade de condições de acesso, permanência e sucesso a todos; ter caráter contínuo e de futuro; contemplar todos os níveis e modalidades de ensino; ser pública, gratuita e de qualidade; dentre outras.

Para isso, a referida autora já apontara, no final da década de 1990, a urgência na revisão total da LDB e seu arcabouço legal, principalmente no tocante às responsabilidades pela formação de professores. Alguns pontos levantados pela autora a fim de centrar esforços para garantir os estudos no campo das Ciências da Educação e das teorias pedagógicas e epistemológicas em todos os processos formativos articulados, orgânicos e sustentados nos princípios da base comum nacional; a revisão nos critérios de credenciamento e reconhecimento dos cursos de formação de professores; jornada única, integral e de dedicação exclusiva com piso salarial assegurada na aprovação de diretrizes da carreira do magistério; e na criação de Centros de Formação de Professores no lugar dos polos da Universidade Aberta do Brasil (UAB) com a participação dos educadores das universidades (FREITAS, 2007).

No Brasil, antes da vigência do PARFOR, existiram outros programas formativos de caráter compensatório cooperados com os sistemas de ensino dos estados e municípios, em concepções ancoradas na epistemologia da prática e direcionadas ao trabalho pedagógico do professor em contraposição à epistemologia das Ciências da Educação. Tais programas foram os Centros de Pesquisa e Desenvolvimento da Educação como parte integrante da Rede Nacional de Formação Continuada de professores, que promoveram ações formativas como o Pró-Formação, em 1997, e o Próinfantil e o Pró-letramento em 2005 (FREITAS, 2007). 
O PARFOR surgiu no ano de 2009, como resultado de ações da Política Brasileira de Formação dos Profissionais do Magistério, legitimada pela Portaria Normativa n 9, de 30 de junho de 2009 (BRASIL, 2009). Configura-se em uma proposta de formação de professores em regime de colaboração entre as Secretarias de Educação dos Estados, Distrito Federal e Municípios e as Instituições Públicas de Educação Superior (IPES), realizada em conjunto com o Ministério da Educação (MEC) e Coordenação de Aperfeiçoamento de Pessoal de Nível Superior (CAPES) ${ }^{4}$, cuja finalidade é atender a demanda por formação inicial em curso de nível superior e de educação continuada dos professores em exercício nas escolas das redes públicas de educação básica do território brasileiro, conforme exigência da Lei $n^{\circ}$ 9.394/96. Tais cursos são ofertados em três condições: como primeira licenciatura para os professores não graduados; como segunda licenciatura para os professores já licenciados que atuam fora de sua área de formação; e como formação pedagógica para bacharéis sem licenciatura.

$\mathrm{Na}$ partilha de responsabilidades no regime de colaboração, cabe aos sistemas estaduais e municipais de educação o suporte necessário para o desenvolvimento das atividades em comum acordo com as IES; à CAPES e ao FNDE, no âmbito do MEC, cabem garantir as despesas por meio de dotações orçamentárias anuais. Após dois anos de implantação do PARFOR, foram registrados que "em 2011, estavam previstos 510 milhões de reais para bolsas a professores formadores e custeio de atividades" (GATTI; SÁ; ANDRÉ, 2011, p. 55).

As referidas autoras, ao debaterem a política de formação inicial de professores no Brasil, analisam algumas experiências do PARFOR e apontam condições asseguradas no Plano a serem consideradas pelas instituições envolvidas no processo formativo dos professores. No entanto, detectamos que, entre as concepções defendidas e as práticas desenvolvidas, muitos

\footnotetext{
${ }_{4}^{4}$ Pela Lei $n^{0} 11.502$, de 11 de julho de 2007, a CAPES passa a gerenciar os programas de formação inicial e continuada da educação básica, cumprindo o papel de agência reguladora e financiadora deste processo formativo. No caso do PARFOR, acompanha os planos estratégicos dos estados que, juntamente com as IES partícipes, cumprem o papel de propor cursos superiores que deem respostas aos problemas locais e regionais, respaldadas pelos Fóruns Estaduais Permanentes de Apoio à Formação Docente.
} 
aspectos deixaram de ser cumpridos e outros surgiram durante a trajetória de formação, principalmente nos aspectos administrativos, financeiros, formativos e os relativos às particularidades dos territórios onde desenvolveram-se as formações.

Em relatório de Silva Júnior (2010), referenciado por Gatti; Sá e André (2011), são apontadas algumas questões avaliadas na formação de professores realizada pela Universidade do Estado da Bahia (UNEB). A primeira delas diz respeito à concepção de professor reflexivo defendida no projeto de formação do Estado como princípio pedagógico e sua não efetivação no conjunto das ações desenvolvidas, salvo exceções em alguns componentes curriculares. Aliado a isso, questiona-se o tipo de reflexão defendido nesta formação, uma vez que a mesma restringe-se à sala de aula, de forma individual, e deixa de ser fomentado em contextos mais amplos, com caráter crítico e continuado.

Outra questão avaliada por Silva Júnior (2010) acena em direção às propostas curriculares dos cursos da UNEB, devido o plano curricular do PARFOR ter sido planejado em nível nacional para ser executado nas instituições formadoras com as devidas adequações às suas particularidades. No entanto, detectamos estar a proposta formativa desconexa das origens e vínculos funcionais dos professores das universidades e das redes de ensino às quais pertencem; também observamos que as condições de trabalho dos professores-formadores, professores-estudantes e dos contextos locais, territoriais e das experiências de trabalho dos professores-estudantes distanciam-se da formação em tela.

Acrescenta-se ainda nesta avaliação aspectos institucionais em que os cursos do PARFOR estão inseridos em uma estrutura universitária departamentalizada que corroboram para a fragmentação do trabalho e da formação. Assim, Silva Júnior (2010) propõe a criação de Centros Regionais de Formação, Pesquisa e Desenvolvimento, que teriam o papel inovador na UNEB de fazer interface entre a formação dos professores da Educação Básica e a prática de estudos investigativos neste campo. Consequentemente, tal proposição, também contribuiria para inovar os 
currículos dos cursos de formação de professores e as próprias estruturas administrativas e dos critérios de gestão ainda muito engessadas da UNEB.

Gatti, Sá e André (2011) ao analisar o relatório de Vosgerau (2010) sobre o PARFOR na Universidade Federal do Semiárido do Rio Grande do Norte (UFERSA) visualizam alguns aspectos relevantes e outros fragilizados que carecem, cautelosamente, serem revistos para a melhoria dos cursos e do próprio Plano.

Com relação aos aspectos relevantes, é perceptível, na fala das autoras, a definição e a clareza dos papéis a serem desempenhados por cada instituição no sentido de consolidar o regime de colaboração, dentre os quais os concernentes à competência da Secretaria de Educação, da UFERSA, das escolas e da própria União Nacional dos Dirigentes Municipais de Educação (UNDIME), mesmo fazendo-se, no relatório de Vosgerau (2010), alusão a sua pouca participação no processo. É possível identificar ainda a existência de certa aproximação da Universidade com as escolas; os cursos não são aligeirados; os materiais didáticos e bibliográficos são atualizados; percebe-se a articulação do PARFOR com o Fórum Estadual Permanente de Apoio à Formação Docente (FORPROF); há preocupação quanto ao grau de recuperação de estudos dos alunos em sua trajetória formativa; todos os professores formadores são do quadro da Universidade, a maioria composta por mestres e doutores; e existe uma iniciativa da Secretaria Estadual de Educação (SEE) em realizar censo educacional próprio para saber as reais necessidades de formação dos professores, além de enviar representantes das universidades para orientar as secretarias municipais de Educação no trâmite processual dos critérios de validação da inscrição e seleção dos candidatos às vagas nos cursos do PARFOR.

No relatório em análise também são visualizados por Vosgerau (2010) alguns aspectos frágeis nas questões físico-administrativos, tais como: falta de estrutura do campus; ausência de coordenadores locais em diferentes campi universitários; inexistência de sistema acadêmico para atendimentos; falta de alimentação e transporte; não concessão de bolsas de estudo e ajuda de custo; execução do plano estratégico que não auxilia os gestores 
das escolas; não liberação de alguns estudantes professores para frequentarem os módulos dos cursos, sendo que muitas vezes precisam pagar um professor substituto com seus próprios proventos; e a obrigatoriedade de permanência dos estudantes professores nos campi para a realização de visitas técnicas de coordenadores do PARFOR.

Com relação à questão pedagógica, Vosgerau (2010) detecta que alguns estudantes professores dos cursos não atuam como professores regentes nos sistemas públicos de ensino; professores formadores atuando sem experiência em cursos de licenciatura; prevalência de carga horária nas disciplinas específicas em detrimento às pedagógicas, com fortes marcas mais para o bacharelado que para licenciatura; e os estágios são realizados como mera formalidade técnica e não como espaço de feituras de novas aprendizagens e novos saberes. Tais pontos relevantes e fragilidades também podem ser detectados no PARFOR no território amazônico.

\section{O PARFOR: antecedentes e particularidades no território amazônico}

A construção do plano de formação docente no estado do Pará em caráter cooperativo e colaborativo entre os sistemas de ensino e instituições públicas de ensino superior remonta da metade da primeira década dos anos 2000. A razão pela qual justifica-se a proposição do referido plano provém dos índices alarmantes detectados na educação básica decorrentes da ausência de consistentes políticas públicas educacionais e de formação de professores em nível local e nacional.

Segundo dados estraídos do Plano de formação docente do Pará (2009), cerca de $10 \%$ dos professores do estado, naquele período, possuíam graduação; os demais estavam no rol dos sem graduação ou que, mesmo a possuindo, atuavam profissionalmente fora de sua área de formação.

É importante lembrar que existiam no mesmo período, na esfera federal, alguns programas que compunham a política de formação de professores e faziam interface com o sistema de ensino público do estado Pará e Universidades públicas, no caso, o Pró-Letramento e o Programa de Formação continuada em alfabetização e Matemática, da Secretaria de 
Educação Básica do MEC, em que parcela dos professores deles participavam. Porém, tal participação ocorria de forma muito restrita, pois mencionados programas centravam-se em níveis, modalidades, disciplina ou áreas afins de atuação do professor, deixando de fora a grande demanda do ensino fundamental.

Carvalho (2012) e Brito (2014), ao discutirem a formação de professores no estado do Pará, apontam três elementos estratégicos: o Fundo de Manutenção e Desenvolvimento do Ensino Fundamental (FUNDEF), o Fundo de Manutenção e Desenvolvimento da Educação Básica (FUNDEB) e o PARFOR.

Carvalho (2012), em sua análise, lembra que o FUNDEF foi criado pela Emenda Constitucional $n^{\circ} 14$, regulamentado pela Lei $n^{0} 9.424 / 96$ e pelo Decreto $n^{\circ}$ 2.264/97, durante o período compreendido entre 1996 e 2006. Neste período foi possível aglutinar recursos financeiros aos estados e municípios, sendo que $60 \%$ destes recursos foram aplicados com prioridade na remuneração dos profissionais do magistério em efetivo exercício na rede pública de ensino e na formação de professores leigos durante os cinco primeiros anos de vigência do fundo. Os $40 \%$ restantes desses mesmos recursos foram direcionados às outras ações de manutenção e desenvolvimento do ensino fundamental, dentre elas a formação inicial dos profissionais do magistério, em nível superior, em diversas licenciaturas a partir de 2002.

Já a criação do FUNDEB pela Lei n 11.494/2007, cuja proposta é funcionar até o ano de 2021 (14 anos) em todo o território brasileiro. Entretanto, Carvalho (ibidem), ao analisar o seu funcionamento no Pará, entre os anos de 2007 a 2009, nos aponta elementos que possibilitam verificar certo avanço na formação dos professores com certificação apenas do ensino médio, pois ao cursarem as licenciaturas das diversas áreas do conhecimento conseguiram atingir a graduação em vários cursos.

O autor em tela chama a atenção que, antes da vigência desses fundos, o quadro total de 37.605 professores atuantes na educação básica em 1996, apresentava a seguinte situação: 3.952 (11\%) possuíam o ensino 
fundamental completo; 20.686 (55\%) o ensino médio-modalidade Normal/Magistério; e 2.577 (6,9\%) tinham o Ensino Médio regular. Com relação ao ensino superior, foi detectado que 9.750 (25,9\%) eram licenciados e apenas 640 (1,7\%) portavam certificação de ensino superior sem licenciatura.

É importante ressaltar que as criações do FUNDEF e FUNDEB contribuíram quantitativamente para o aumento do número de professores com formação em cursos de licenciatura plena, com a possibilidade de muitos municípios investirem na formação inicial de professores, mediante a contratação de universidades públicas e privadas com recursos provenientes desses fundos. A qualidade desses cursos foi muito questionada em função da forma, critérios e condições em que foram ofertados em diversas localidades do território paraense, como destacam Maues (2003); Nunes, Monteiro e Santos (2008), ao intitularem esse fenômeno de universitarização dos professores e, no estado do Pará, tal episódio não foi diferente.

Nunes, Monteiro e Santos (2008) alertam que a universitarização decorre em função da extinção do Curso Médio Normal no Brasil em um efeito cascata, antes mesmo de findada a década da educação (19972007) e por exigência da legislação vigente à época, principalmente os art. 62 e 87 da Lei no 9.394/96. No estado do Pará, a decisão de extinção do referido Curso é referendada no ano de 2003, por meio da Resolução CEE/PA n' 271, de 02 de maio de 2000, em meio a muitas controvérsias, equívocos e contradições.

Toda a circunstância histórica no Brasil e no Pará foi decisiva na corrida por oferta de cursos superiores de forma desenfreada e de qualidade questionável, pois eram ofertadas fora da Universidade de forma aligeirada e centrada e com foco somente no ensino, sem considerar a totalidade do trabalho acadêmico e científico.

Para Mavés (2003), o processo de universitarização está associado às exigências da globalização do mundo, sendo o professor considerado o coadjuvante para desempenhar novas funções frente a demanda da nova ordem mundial. Em muitos países como França, Inglaterra e Brasil foram 
iniciadas reformas nos modelos de formação docente ao exigí-la em nível superior sobre o argumento de melhor qualificar o professor, ao elevá-la de patamar e aprofundar conhecimentos para dominar o exercício da função. No entanto, entre o discurso e a materialização da mudança muitas situações são deturpadas, tomam rumos diferentes e nem sempre contemplam a contento a qualidade anunciada, pois:

a formação se dá na realidade em nível pós-médio, ou seja, em instituições de nível superior, mas sem obdecer aos princípios básicos da indissociabilidade entre ensino, pesquisa e extensão, que caracterizam a instituição Universidade [...] (MAUÉS, 2003, p. 167).

Tal afirmação corrobora com o entendimento do caso brasileiro ao garantir na legislação a admissão da formação em nível médio na medida em que também cede espaço à instituicionalização dos ISEs, quer seja na esfera pública, quer seja na privada. No último caso, é importante frisar a prevalência de oferta dos cursos privados de formação de professores para a educação infantil e anos iniciais do ensino fundamental com a preocupação central em formar mão de obra para o mercado de trabalho de forma aligeirada.

Portanto, no processo de universitarização observa-se grande preocupação com a transmissão de saberes e conhecimentos funcionais para o exercício profissional. Contudo, a preocupaão em construí-lo com o rigor científico e acadêmico, cujo lócus é a Universidade, fica em plano secundário.

No ano de 2009 o governo do Pará implementou o Plano de Formação Docente do Estado do Pará ao aderir ao PARFOR por meio de assinatura do Termo de Adesão ao Acordo de Cooperação Técnica (ACT) de 28/05/09, publicado no Diário Oficial da União (DOU) de 27/07/09, destinado a atender professores das redes estadual e municipais de ensino para a oferta gratuita de curso superior por IES públicas. No Pará, o Plano significou a continuidade do processo formativo dos professores ainda não contemplados com formação superior, mas em pleno exercício profissional nos níveis de escolaridade da educação básica. 
Em termos quantitativos, significa o atendimento da demanda de 66.844 professores de 20 municípios polos/URE que historicamente clamam por formação específica. O referido Plano foi implantado por meio de assinatura de um protocolo de cooperação entre Secretaria de Estado de Educação e Qualidade do Ensino (SEDUC), Instituto Federal de Educação, Ciência e Tecnologia do Pará (IFPA), Universidade do Estado do Pará (UEPA), Universidade Federal do Oeste do Pará (UFOPA), Universidade Federal do Pará (UFPA) e Universidade Federal Rural da Amazônia (UFRA).

Brito (2014), em estudo realizado sobre o PARFOR no período compreendido entre 2009 a 2014, avaliou o impacto deste Plano no âmbito da UFPA e ao ouvir professores e alunos verificou se os objetivos naquele momento estavam sendo atingidos. Neste estudo, ela analisa o PARFOR no conjunto das políticas públicas, como proposta de formação inicial de professores e seus impactos no estado do Pará, e coaduna com a ideia de que o PARFOR possui grande relevância social e governamental, pois pode efetivar o direto social de estudar aliado ao direto à educação, assegurado na carta magna brasileira de 1988 (BRASIL, 1988). Este direito pode suprir a condição de milhões de brasileiros analfabetos, repetentes, evadidos da escola por falta de oportunidades e condições dignas de vida. Ainda para a autora, a década de 2000 foi contemplada com o Plano de Desenvolvimento da Educação (PDE), a Lei n 9.394/96 e o Programa de Aceleração do Crescimento (PAC) como forma de assegurar maior qualidade à educação e, consequentemente, o avanço econômico do país, mesmo sendo outras profissões mais atrativas, financeiramente melhores e mais reconhecidas que o magistério.

Com relação ao estado do Pará, Brito (2014) enfatiza que a UFPA iniciou o Plano ao ofertar 14 turmas, com 470 alunos, nos cursos de Ciências Naturais, Geografia, História, Pedagogia, Matemática e Letras/Língua Portuguesa, abrangendo os campi de Bragança, Belém, Abaetetuba e Cametá. Até 2013 foram ofertadas 287 turmas, no total de 10.403 professores em exercício matriculados com perspectiva de aumento gradativo de matrículas e de municípios contemplados nos anos que se seguiram. 
No âmbito da UEPA, o PARFOR começou em 2009, por meio da oferta de cursos de Licenciatura em Pedagogia, Letras Língua Inglesa, Letras Língua Portuguesa, Licenciatura Intercultural Indígena, Licenciatura em História, Ciências da Religião, Educação Física e Licenciaturas em Ciências Naturais, Matemática, Geografia e Filosofia. Até o ano de 2016, o PARFOR na UEPA totalizava 53 turmas em andamento, resultado do ingresso nos anos de 2012 , 2013, 2014 e 2016. Destas, 9 já haviam sido concluídas até o final do ano em evidência. No ano de 2017 o PARFOR atingiu os municípios de Anajás, Salvaterra, Redenção, Belém, Castanhal, Barcarena, Paragominas, Breves, São Miguel do Guamá, Santarém, Oriximiná, Vigia, Conceição do Araguaia, Cametá, Igarapé-Açu, São Félix do Xingu, Acará, Capitão Poço, Melgaço, Alenquer, Marituba e São Sebastião da Boa Vista (UEPA, 2017).

Em relatório de avaliação do PARFOR/Pará (2013), a comissão avaliadora local apontou que até o ano de 2011 os índices de professores com formação em nível superior ainda permaneciam baixos em relação à média nacional, pois enquanto no Pará totalizava-se 46\%; no Brasil era de $68,9 \%$, demonstrando um desequilíbrio que interfere diretamente nos indicadores do Índice de Desenvolvimento da Educação Básica (IDEB) do estado do Pará.

O quadro apresentado impulsionou os gestores de políticas públicas a intensificarem a formação pelo PARFOR com o intuito de melhorar a qualificação dos professores no Pará a partir da elevação dos cursos de licenciaturas ofertados aos professores em exercício, pois foi:

assumido no Estado do Pará por todas as Instituições Públicas de Ensino Superior (IPES), que ofereceram até 2012, 575 turmas para 22.000 professores em setenta e um (71) polos, atingindo os cento e quarenta e quatro (144) municípios do Estado (PARÁ, 2013, p. 7).

No entanto, era imprescindível avaliar a qualidade da formação e verificar seus impactos nas salas de aulas das escolas. Isso gerou a premência de detectar as fragilidades e potencialidades do PARFOR, tomando por base o papel das IPES, do estado e a efetividade acadêmica do plano, perpassando pela prática pedagógica do professor formador e 
pelas condições de ingresso dos professores estudantes no Plano; dentre outros pontos que adentram às questões materiais, citamos as infraestruturais, financeiras e administrativas.

Dentro da logística exposta, foram ouvidos professores formadores, estudantes professores, gestores públicos e das instituições envolvidas, a fim de buscar indícios reveladores de possíveis caminhos para melhoria da formação dos professores. O processo perpassou pela adoção das concepções críticas de avaliação assentadas em sete dimensões, a saber: 1: Orçamento e Gestão do PARFOR; 2: Organização Didático-Pedagógica; 3: Corpo Docente; 4: Administração Acadêmica; 5: Instalações Físicas e Funcionamento do Polo; 6: Incentivo ao Acesso e Permanência; e 7: Efeitos da Formação do PARFOR. Neste relatório os professores formadores responderam até a dimensão 5 e os professores-estudantes a todas as dimensões, exceto a dimensão 3.

Algumas fragilidades registradas na avaliação dos professores estudantes merecem destaque, aquelas relacionadas à/ao: ajuda dos municípios e estado aos professores estudantes para frequentarem os cursos pelo PARFOR em que poucos recebem ajuda de custos (23\%); desconhecimento do projeto pedagógico do curso (61\%); pouca atividade de Extensão (70\%); dificuldades em frequentar eventos científicos que sejam considerados atividades complementares a serem creditadas no curso devido às dificuldades financeiras, de deslocamento e dispensa para participar, uma vez que estão em horários de trabalho (75\%); não disponibilidade de Laboratórios para aulas práticas (71\%); insatisfação com os mobiliários, equipamento e material de consumo dos laboratórios existentes (62\%); e polos que não possuem biblioteca e acervo bibliográfico para consulta dos alunos (37\%).

Como pontos fortes o relatório aponta $a(s) / o(s)$ : práticas e experiências docentes levadas em consideração no processo formativo do PARFOR (79\%); conteúdos curriculares ministrados de forma contextualizada e problematizadora (95\%); laboratórios de Informática com acesso a internet disponíveis para uso do professor aluno (60\%); realização das atividades à 
distância exigidas nos cursos (68\%), mas ainda apontam que há dificuldade de acesso com o sinal de internet para usar a plataforma Moodle, que em parcela significativa das vezes é solucionado por contato via e-mail individual ou outros recursos midiáticos como aplicativos de redes sociais; acessibilidade à estrutura física dos polos é razoavelmente boa (60\%).

De modo geral, percebemos nas respostas dos professores formadores e professores estudantes algumas aproximações, principalmente nas questões de melhoria da infraestrutura dos polos, no aspecto pedagógico para estabelecer a indissociabilidade entre ensino-pesquisa-extensão e no conhecimento do projeto do curso onde professores formadores e professores estudantes irão formar e formar-se.

No entanto, a dimensão 7, referente aos efeitos que a formação desenvolvida pelo PARFOR surtiu nos professores estudantes é altamente significativa, pois as respostas convergem a uma unanimidade no grau de satisfação ao impactar: na prática dos professores estudantes (100\%); nas suas maiores participações nas atividades da escola (99\%); nas atividades de integração escola-comunidade onde atuam como professores regentes (96\%); na realização de pesquisa na escola (69\%) e na expectativa de continuidade de estudo após concluírem seus cursos (100\%).

\section{CONSIDERAÇÕES FINAIS}

Neste artigo descrevemos as interferências dos organismos internacionais na definição das políticas formativas docente no Brasil e, particularmente, na formação inicial de professores, por meio do PARFOR, com reflexos no estado do Pará e esperamos ter contribuído, mesmo que inicialmente, para esclarecer algumas questões aqui expostas.

No que diz respeito aos organismos internacionais percebemos certa complacência do governo brasileiro em acatar as orientações e recomendações destes, em especial as do FMI, OCDE e BM, e ajustá-la ao ideário neoliberal para atender as exigências do mercado e do capital, em que a educação e a formação de professores são usadas como áreas estratégicas neste cenário. 
Desvelamos que o PARFOR desde sua gênese configura-se de várias formas no território brasileiro; ora congregados com a UAB e outros programas de formação de professores propostos pelo MEC, presencial e a distância; ora integrados aos próprios modelos formativos adotados pelas redes de ensino e universidades de algumas localidades do país, como é o caso do Plano na Amazônia.

É possível detectar que o PARFOR, mesmo sendo considerado por muitos gestores de políticas públicas educacionais uma iniciativa formativa diferenciada, ainda apresenta dilemas e tensões a serem superados. São problemas de ordem técnica, administrativa, estrutural, financeira, didáticopedagógica e organizacional, localizadas em estruturas institucionais (universitárias, sistêmicas, escolares, representativas, de governo, dentre outras) engessadas e precárias, cujas formas de gestão centralizam-se em modelos tecnocratas e burocráticos que emperram os fluxos de informações e práticas exequiveis de trabalho e em estruturas físicas sem condições de funcionamento dos cursos, sem logística e suporte. Notamos, no PARFOR de modo geral e, em especial na Amazônia, que faltam critérios mais consistentes para seleção dos estudantes professores e professores formadores, pois muitos não encontram-se em regência de sala de aula e outros, tampouco, têm a experiência de atuação com formação docente em licenciaturas; não há deferimento de questões em benefício aos estudantes professores como liberação para estudo sem prejuízos de seus vencimentos, ajuda de custo e outras formas de incentivo para frequentarem os cursos de formação, acompanhamento pedagógico deficitário, dentre outros.

Para inverter a tendência predominante da lógica exposta seriam necessárias mudanças na cultura organizacional das instituições envolvidas no processo formativo, como as concepções de gestão e administração, na partilha de responsabilidades, no comprometimento e envolvimento dos profissionais que nelas atuam em um novo regime de colaboração/corresponsabilidades mútuas e recíprocas, configurando uma nova engenharia interinstitucional global, ampla e coparticipante. 
De outro lado, entendemos que a proposta curricular do PARFOR pensada de forma única para todo o território brasileiro se configura em problema visceral, pois muitas vezes funciona com o mesmo currículo dos cursos regulares e em defesa de um tipo de concepção de formação (reflexivo, reflexivo crítico) deslocada da realidade existencial e material dos estudantes professores e da instituição formadora.

Acreditamos na prevalência de uma concepção de formação geral, ampla, crítica, plural e que na construção da proposta curricular dos cursos de formação do PARFOR sejam garantidos os conhecimentos epistemológicos das áreas da Ciência da Educação, conhecimentos concernentes à cultura local e outros diversos saberes importantes na formação dos professores. Além disso, devem ser adotadas atividades pedagógicas que considerem as experiências profissionais dos professores estudantes, com cargas horárias específicas em um tipo de alternância entre a universidade, os cursos e os contextos de trabalho em um movimento dialético que certamente contribuiria para a efetivação da indissociabilidade entre ensino, pesquisa e extensão, tanto na Amazônia quanto em outras localidades do Brasil.

\section{REFERÊNCIAS}

BASTOS, R. dos S. A Formação de Professores de Educação Física no PAFOR: implicações na Organização do Trabalho Pedagógico Belém, 2013. 198 f. Dissertação (Mestrado em Educação) - Universidade do Estado do Pará, Belém, 2013.

BRASIL. Constituição Federal do Brasil. Brasília-DF,1988.

BRASIL. Emenda Constitucional $n^{\circ} 14$, de 12 de setembro de 1996. Modifica os arts. 34, 208, 211 e 212 da Constituição Federal e dá nova redação ao art. 60 do Ato das Disposições constitucionais transitórias. Brasília-DF, 1996a.

BRASIL. Lei n $^{\circ}$ 9.394, de 20 de dezembro de 1996. Estabelece as diretrizes e bases da educação nacional. Diário Oficial da União, DF, 23 dez. 1996b.

BRASIL. Lei $n^{\circ}$ 9.424, de 24 de dezembro de 1996. Dispõe sobre o Fundo de Manutenção e Desenvolvimento do Ensino Fundamental e Valorização do Magistério. Brasília-DF, 1996c. 
BRASIL. Decreto n².264, de 24 de junho de 1997. Regulamenta a lei 9.424 de 24 de dezembro de 1996, no âmbito federal e determina outras providências. Brasília-DF, 1996d.

BRASIL. Ministério da Educação. Plano de Desenvolvimento da Educação (PDE): razões, princípios e programas. Brasília, 2007a.

BRASIL. Lei $\mathrm{n}^{\circ}$ 11.494, de 20 de junho de 2007. Regulamenta o Fundo de Manutenção e Desenvolvimento da Educação Básica. Brasília-DF, 2007b.

BRASIL. Lei $n^{\circ}$ 11.502, de 11 de julho de 2007c. Modifica as competências e a estrutura organizacional da fundação Coordenação de Aperfeiçoamento de Pessoal de Nível Superior. Brasília-DF, 2007.

BRASIL. Decreto $n^{\circ}$ 6.253, de 13 de novembro de 2007. Revoga o decreto $n^{\circ}$ 2.264, de 24 de junho de 1997 e dispõe sobre o FUNDEB. Brasília-DF, 2007d.

BRASIL. Conselho Nacional de Educação. Portaria Normativa $\mathbf{n}^{\circ} \mathbf{9}$, de $\mathbf{3 0}$ de junho de 2009 que institui o PARFOR no âmbito do Ministério da Educação. Brasília-DF, 2009.

BRASIL. Ministério do Planejamento. Portal Programa de Aceleração do Crescimento (PAC). Disponível em: http://www.pac.gov.br/sobre-o-pac. Acesso em: 20 fev. 2018.

BRASIL. Portal CAPES. PROFIC. Disponível em: http://capes.gov.br/sala-deimprensa/noticias/8567-formacao-de-professores-em-atividade-tera-novomodelo. Acesso em: 25 set. 2017.

BRITO, F. L. de. Políticas Públicas na Educação: os impactos do PARFOR no Estado do Pará a partir da UFPA. 2014.

CARVALHO, F. A. F. Repercussões do FUNDEF/FUNDEB na Formação dos professores da Rede Estadual de Ensino do Pará. ICED/UFPA, 2012.

FERREIRA, D. L. A Organização para Cooperação e Desenvolvimento Econômico (OCDE) e a política de formação docente no Brasil. 201 1, 330f. Tese (Doutorado em Educação) - Universidade Federal do Pará, Belém/PA, 2011.

FREITAS, H. C. L. Certificação docente e formação do educador: regulação e desprofissionalização. Educ. \& Soc., Campinas, v. 24, n. 85, p. 1095-1124, dez. 2003.

FREITAS, H. C. L. A (Nova) Política de Formação de Professores: a prioridade postergada. Educ. Soc., Campinas, v. 28, n.100 - Especial, p. 1203-1230. out 2007. 
GATTI, B. A.; SÁ, E. S. de; ANDRÉ, M. E. D. de A. Políticas docentes no Brasil: um estado da arte. Brasília: UNESCO, 2011.

GRUPO BANCO MUNDIAL. Um ajuste justo: análise da eficiência e equidade do gasto público no Brasil. Vol. I, síntese. Novembro, 2017.

MAUÉS, O. C. A política da OCDE para a Educação e a formação.

Educação, Porto Alegre, v. 34, n 1, p. 75-85, jan./abr. 2011.

MAUÉS, O. C. As políticas de formação de professores: a universitarização e a prática. Série-Estudos. Periódico do Mestrado em Educação da UCDB,

Campo Grande-MS, n 16, p. 165-179, jul./dez. 2003.

MÉSZÁROS, I. A Educação para além do Capital. São Paulo: Boitempo, 2005. $128 p$.

MONLEVADE, J. A.; SILVA, M. A. Quem manda na educação no Brasil? Brasília: Idéa, 2000.

NUNES, C. do S. C. N.; MONTEIRO, A. L.; SANTOS, T. R. L. dos. A formação de professores em Nível Médio no Pará: política, motivações e aspirações profissionais dos alunos. Belém: EDUEPA, 2008.

OCDE. La qualité du personnel enseignant. 2004. Disponível em:

<http://www.oecd.org/dataoecd/0/8/31589487.pdf>.Acesso em: nov. 2008.

OCDE. Professores são importantes. Atraindo, desenvolvendo e retendo professores eficazes. São Paulo: Coedição Moderna: OCDE, 2006 a.

OCDE. Le capital Humain: comment Le savoir détermine notre vie. Paris (FR): OCDE, 2007a.

OCDE. Politiques d'éducation et de formation. Paris (FR): OCDE, 2007b.

OCDE. Comprendre IIImpact Socail de I' Éducation. 2007c. Disponível em http://www.oecd.org/document/44/0,3343,fr_2649_35845581_39439340_1_1_1 _l,00.html. Acesso em: 22 jan. 2010

OCDE. Education at a Glance 2009. OECD Indicators. Paris (FR): OECD, 2009. Disponível em: http://www.oecd.org/dataoecd/41/25/43636332.pdf. Acesso em: 21 jan. 2010.

OCDE. L'éducation aujourd'hui: La Perspective de L'OCDE. Paris (FR): OCDE, $2009 b$.

PARÁ. Plano Decenal de Formação docente do Estado do Pará. Protocolo SEDUC/IES. Belém, Pará. 2009. 
PARÁ. Plano de Formação continuada de educadores do Estado do Pará. Protocolo SEDUC/IES. Belém, Pará. 2011.

PARÁ. Relatório da Avaliação do Plano Nacional de Formação Docente PARFOR/PARÁ. Belém, 2013.

PINTO, D. Fontes de Souza. OCDE: uma visão brasileira. Brasília: IRBr; FUNAG, 2000 (Coleção 'Curso de Altos Estudos do Instituto Rio Branco').

SILVA JÚNIOR, C. A. Fortalecimento das políticas de valorização docente: proposição de novos formatos para cursos de licenciatura para o estado da Bahia; relatório. Brasília: CAPES, UNESCO, 2010. (Documento interno).

SMITH, A. A Riqueza das Nações: investigação sobre sua natureza e suas causas. Tradução de Luiz João Baraúna. Vol. II, Livro V, cap.1. Coleção Os Economistas. 1996.

UEPA, SITE. Informativo PARFOR. Disponível em: http://www.vepa.br/ptbr/pagina/parfor. Acesso em: 23 jun. 2017.

VOSGERAU, D. S. R. Fortalecimento das políticas de valorização docente: diagnóstico de avaliação de cursos presenciais de licenciatura ofertados pelo PARFOR - UFERSA (Universidade Federal do Semiárido). Rio Grande do Norte: relatório. Brasília: CAPES, UNESCO, 2010. (Documento interno).

Recebido em: 09 de fevereiro de 2019 Aprovado em: 20 de agosto de 2019 